\title{
Excelling at selling: The charming personality style predicts occupational activities, sales performance, and persuasive competence
}

\author{
Miguel Kazén, ${ }^{1}$ Julius Kuhl, ${ }^{1}$ Sylvie Boermans, ${ }^{2}$ and Sander L. Koole ${ }^{3}$ \\ ${ }^{1}$ University of Osnabrück, Osnabrück, Germany, ${ }^{2}$ Catholic University of Leuven, Leuven, Belgium, \\ ${ }^{3}$ VU University, Amsterdam, The Netherlands
}

\begin{abstract}
The present research investigates how individual differences in charming personality are related to occupational activities, sales performance, and persuasive competence. Study 1 showed that sales representatives had higher scores on the charming personality style than executive managers. Study 2 showed that the charming personality style predicted actual sales performance among branch managers of a large German insurance company over a period of 2 years; the explicit power motivation served as a mediator in this relation. Finally, Study 3 , carried out in a laboratory setting, confirmed the hypothesis that a charming personality is associated with persuasive competence, which suggests that this style is more relevant for sales representatives than for executive managers. The authors conclude that the charming personality style represents an important psychological resource for organizations.
\end{abstract}

Keywords: charming personality; job selection; persuasion; power motivation; sales performance

Correspondence: Dr. Miguel Kazén, Faculty of Human Sciences, Institute of Psychology, University of Osnabrück, 49074 Osnabrück, Germany. Email: mikazen@uos.de

Received 10 February 2012. Accepted 25 October 2012.

Charm is a way of getting the answer yes without asking a clear question.

Albert Camus, The Fall, 1956

In today's information age, commercial businesses and industries have become increasingly dependent on their human resources. Faced with volatile consumer preferences and technologies that are changing at a rapidly accelerating rate, managers must increasingly rely on the flexibility and ingenuity of their employees to stay ahead of the competition. Commercial organizations therefore need to identify the strengths and weaknesses of employees so that management and training can be tailored to the unique profile of each individual person (DeShon \& Gillespie, 2005). Thus, it is ever more important to understand which individual dispositions underlie the effectiveness and adaptability of the workforce.

The present article highlights the relevance in the workplace of the charming personality style. The charming per- sonality style is associated with positive affect and with having a persuasive impact on others (Kuhl \& Kazén, 2009; McClelland, 1985). The charming personality style is therefore particularly relevant to sales performance. In the following paragraphs, we begin by considering the notion of the charming personality style, then its relation to sales performance, and finally we present three studies that empirically tested our hypotheses.

\section{Personality styles}

The role of personality in the workplace has been amply researched over the past two decades (Hogan, 2005; Kanfer \& Hulin, 1985; Mount, Barrick, \& Stewart, 1998; Ones, Viswesvaran, \& Dilchert, 2005; Warr, Bartram, \& Martin, 2005). A unique feature of the present research is that it is based on a personality classification system using personality styles, defined as the enduring and unique patterns of thinking, feeling, and behaving found in normal 
individuals. Examples are reserved, cautious, conscientious, charming, and self-assertive (Kuhl \& Kazén, 2009). These personality styles are considered as traits and are derived from the well-known classification of personality disorders of the Diagnostic and Statistical Manual of Mental Disorders (DSM-IV; American Psychiatric Association, 2000), namely, schizoid, paranoid, obsessive-compulsive, histrionic, and antisocial, respectively. The taxonomy of personality styles and disorders is thus grounded in observations made by trained clinicians over many decades. The personality styles represent nonpathological response tendencies that may become personality disorders when they are extremely exaggerated and beyond personal control (Fiedler, 1998; Kuhl \& Kazén, 2009; see also Millon, 1994; Millon \& Davies, 2000; Strack, 1999).

Because the taxonomy of personality styles was originally developed in clinical psychology some authors have suggested that these styles reflect the "dark side" of personality (Moscoso \& Salgado, 2004). However, it is more plausible that personality styles are grounded in processes that are adaptive in normally functioning individuals, similar to $\operatorname{cog}$ nitive styles (see Kozhevnikov, 2007). Work on the personality systems interactions (PSI) theory (Kuhl, 2000, 2001) suggests that personality styles arise from interactions between basic personality systems that can be found in all human beings. In this conception, the basic building blocks of personality consist of cognitive-affective-behavioral systems that, at least in principle, can be used by all adult humans to adaptively meet the challenges of their environment.

Through a combination of genetic predisposition and socialization history, individuals may come to use certain personality systems more frequently or preferentially, so that these systems become part of their characteristic personality style. To the extent that personality styles develop as a characteristic response to the recurring problems individuals face, they may be considered adaptive and healthy aspects of personality functioning. Maladaptive and pathological consequences may only arise when individuals become "locked" into a personality style, that is, when individuals become unable to either use personality systems that do not belong to their styles, or respond differently to meet challenges even when doing so would be beneficial and adaptive.

Only few studies to date have investigated personality styles in organizational settings. One relevant study by Moscoso and Salgado (2004) focused on the relation between personality styles and supervisor ratings on a series of job performance variables (e.g., quantity and quality of performance, effort, initiative, etc.). The results revealed negative correlations between seven of these styles (which they called "suspicious," "shy," "sad," "pessimistic," "sufferer," "eccentric," and " risky," using terms with negative connotations) and supervisor ratings of job performance. Nevertheless, we believe that it is premature to conclude that personality styles are always negatively related to job performance. First, Moscoso and Salgado used supervisor ratings to indicate job performance, so that it remains to be seen how personality styles are related to actual job performance. Second, it is theoretically plausible that some personality styles might yield advantages in specific work contexts, provided that they do not become so extreme as to be considered disorders (Lynch \& Horton, 2004; Sperry, 1995). For instance, Sperry observed that individuals with a charming personality, because of their free-spirited character, are likely to experience difficulties in adhering to strict bureaucratic rules and protocols. It is thus conceivable that supervisor ratings are negatively affected by charming individuals' bureaucratic neglect, even when these individuals' objective sales performance is high.

\section{The charming personality style and sales}

In the present article we focus on the charming style and its relevance to occupational activities, sales performance, and persuasive competence. The charming personality style corresponds to the histrionic personality, as described in the DSM-IV (or in the ICD-10: International statistical classification of diseases, [10th revision, 2008 ed.]; World Health Organization, 2008) in the normal nonpathological range (Kuhl \& Kazén, 2009). The main symptoms described in the above manuals for the histrionic personality disorder are integrated in the items of the charming personality style, but in a milder form are adaptive in social situations. We conceptualize the charming personality style as a stable trait (and not as a type), characterized by friendly and cheerful verbal and nonverbal behavior, which is associated with having a persuasive impact on others (Kuhl \& Kazén, 2009). This conceptualization is consistent with the definition of trait given by Winter (2011): "Traits are the consistent stylistic aspects of human personality" (p. 1063). In sum, we propose that the charming personality style is a stable trait associated with positive affect and with a power motivation (having an influence on other people; see McClelland, 1985). 
The charming personality style should therefore facilitate the spontaneous expression of positive affect in social situations, including nonverbal behavior. There is evidence that positive affect facilitates spontaneous behavior whereas negative affect inhibits it (Berridge, 2003; Elliot \& Thrash, 2002; Gray, 1987; Wise \& Rompre, 1989) and also that customers are more likely to buy a product and to have more positive product evaluations when they are brought into a good mood than when they are in a neutral or bad mood (George, 1991, 1998; Isen, Shalker, Clark, \& Karp, 1978). Because of this feature of positive affect in social situations, we expect that the charming personality style will be associated with sales success.

In addition, the charming personality is characterized by an intuitive implementation of the power motive (the latter defined as a tendency to exert an influence on others; cf. McClelland, 1985). The implementation of the power motive is the basis of persuasive competence. In real-life sales situations the importance of persuasive competence cannot be underestimated. Salespeople "must be self-starters, relying on their own initiative and powers of persuasion" (Vinchur, Schippmann, Switzer, \& Roth, 1998, p. 586). Indeed, research indicates that both extrinsic and intrinsic motivation influence how sales people conceive and conduct their profession (Miao \& Evans, 2007). Thus, a personality resource that promotes the initiation of persuasive behavior should be highly conducive to sales performance and could conceivably be related to customer satisfaction. The persuasive competence of the charming personality style is likely to be one such resource. Through its links with the power motive, the charming personality style should lead employees to gravitate towards professional activities involving sales. Moreover, among salespeople, the charming personality style should motivate individuals to initiate directed attempts at persuading and influencing potential customers. The charming personality style should also foster friendly and cheerful verbal and nonverbal behavior, which should further enhance the person's persuasive impact on others (Friedman, Riggio, \& Casella, 1988).

\section{Overview of the present research and hypotheses}

We examined the charming personality style and its relation to occupational activities, actual sales performance, and persuasive behavior. An important implication of our analysis is that the charming personality style should lead individuals to prefer professional activities that allow them to influence others through direct, face-to-face contact. Therefore, in Study 1 we examined the association between the charming personality style and the direct versus indirect commercial activities of sales representatives versus executive managers, respectively. The main hypothesis of the first study was that the charming personality style should be overrepresented in sales representatives compared with executive managers. In addition, because women tend to have a more charming personality style than men (Kuhl \& Kazén, 2009), we also expected a main effect of sex in salespersons, favoring women over men.

Our theoretical analysis holds that the charming personality style facilitates sales performance through a subtle but direct influence on other people. In Study 2, we examined the effects of the charming personality style on actual sales performance among managers of a large commercial company. Our main hypotheses were that the charming personality style would predict actual sales performance over a long period of time and that this relation would be mediated by personality dimensions related to exerting influence on other people.

If the charming personality style is related to persuasive competence, as we propose, it should be related to persuasive behavior, even in a laboratory setting. To test this notion, in Study 3 we examined the effects of the charming personality style on persuasive sales behavior in the laboratory, where we could obtain fine-grained behavioral measurements of such behavior. The main hypothesis of the third study was that the charming personality will predict not only the verbal but also the nonverbal behavior involved in persuasive behavior.

We included measures of positive affect in each study and of power motivation in the first two studies to evaluate the assumption that the charming personality style positively relates to them.

\section{Study 1}

The persuasive powers associated with the charming personality style rely largely on face-to-face interactions. Accordingly, the charming personality style might lead individuals to gravitate towards professions that involve face-to-face contact with customers. If this reasoning is valid, we can expect the charming personality style to be more prevalent among sales persons who work in "eye-to-eye" contact with potential clients. Study 1 tested this main hypothesis among 
a sample of German managers who worked either as sales representatives or executives. Because sales representatives have more direct contact with potential costumers than executives, we predicted that sales representatives would have higher charming personality scores than managers. In addition, because there are known sex differences in the charming personality, with higher scores for women (Kuhl \& Kazén, 2009, Table 13), we also predicted higher scores for female than for male participants.

Finally, Study 1 included a measure of the explicit power motive, to test the notion that the charming personality style is closely associated with motives related to exerting an influence on others. If this is the case, it may be possible that sales representatives have higher power motive scores than executive managers. Note that this expectation is far from self-evident, given that the job of executive managers consists of coordinating the work of other people and influencing them, which might also be considered closely related to power motivation.

\section{Method}

\section{Participants}

Data from 444 German managers were analyzed for this study. There were 169 sales representatives (Vertrieb; 113 men and 56 women; i.e., $66.9 \%$ and $33.1 \%$, respectively) and 275 executives (Führung; 189 men and 86 women; i.e., $68.7 \%$ and $31.2 \%$, respectively). Their mean age was 35 years $(S D=4.81$ years; age range $24-42$ years). The participants voluntarily filled out a series of psychological tests (see Kuhl, Kazén, \& Koole, 2006), including those relevant to our present purposes, from a remote computer in order to obtain feedback concerning their personality characteristics as well as coaching about how to improve their psychological wellbeing. The feedback was obtained in exchange for a fee. The data were made available to us by the Institute for Motivation and Personality Development, Assessment, Research, and Training (IMPART; see http://www.impart.de). The participants were informed that their data could be used for research purposes in an anonymous form.

\section{Personality scales}

The Personality Styles and Disorders Inventory ${ }^{1}$ (PSDI; Kuhl \& Kazén, 2009) measures personality styles within the nonpathological range that are analogous to the personality disorders described in psychiatric diagnostic manuals, such as the DSM-IV. The PSDI has been applied to a sample of
1,940 persons and there are separate norms for sex and five age-ranges. Each of its scales has been validated and it has been used in research and applied settings. The PSDI consists of 14 scales measuring the personality styles that correspond to personality disorders. They are, respectively, ambitious/narcissistic, assertive/antisocial, charming/ histrionic, conscientious/compulsive, critical/negativistic, intuitive/schizotypal, loyal/dependent, optimistic/rhapsodic, passive/depressive, reserved/schizoid, self-critical/avoidant, spontaneous/borderline, unselfish/self-sacrificing, and willful/ paranoid. The scales correspond to the eleven DSM-IV personality disorders, with the exception of the optimistic/ rhapsodic, passive/depressive, and unselfish/self-sacrificing scales, which are additionally included in the PSDI.

A confirmatory factor analysis of the PSDI with a sample of 1,227 persons yielded a four-factor solution: (1) "Negative Affect," Eigenvalue $=4.29$, scales (from higher to lower loadings): passive, spontaneous, self-critical, loyal, critical, and unselfish; (2) "Positive Affect," Eigenvalue = 2.73, scales (from higher to lower loadings): charming, optimistic, ambitious, assertive, intuitive, and reserved (with negative sign); (3) "Inhibition of Negative Affect," Eigenvalue = 1.54, scales (from higher to lower loadings): willful, reserved, critical, and assertive; and (4) "Compulsiveness," Eigenvalue $=1.24$, scales (higher to lower loadings): conscientious and unselfish. The communality coefficients of the scales used in this research were .59 (ambitious personality), .76 (assertive personality), and .75 (charming personality).

We applied the short version of the PSDI, which consists of the 14 scales mentioned above, each with four items per scale. Responses were given using a 4-point Likert scale, that is, this statement applies to me not at all (0), somewhat (1), much (2), or completely (3). The charming style scale (in German, liebenswürdig; Cronbach's $\alpha=.71$ ) was the focus of the present research; illustrative items are "I can be very charming when I want to persuade someone of something" and "I am very spontaneous in approaching other people and making contact with them." We investigated two other scales of the PSDI that load on the same factor as the charming personality (positive affect, see previous paragraph) and which are related to high levels of performance or to influencing others, respectively. The first was the ambitious style scale (Cronbach's $\alpha=.68$ ); illustrative items are "The thought of becoming a famous personality excites me" and "I wish that more people would notice what is special in me." The second was the assertive style 
scale (Cronbach's $\alpha=.78$ ); illustrative items are "When others want something that I also need, I usually get it myself" and "When others make troubles for me, I can become very unpleasant."

To measure explicit power motives, we used the Motive Enactment Test (MET; see Kuhl \& Henseler, 2004; for more information about this test, see Kazén \& Kuhl, 2011; Kuhl et al., 2006). The MET is a self-report inventory that measures how power, achievement, and affiliation motives are implemented (in an integrative, intuitive, controlled, or anxious way), and consists of 15 main subscales with four items each. Five subscales relate to the power motive, five to the achievement motive, and five to the affiliation motive. Responses are given using a 4-point Likert scale: This statement applies to me not at all (0), somewhat (1), much (2), or completely (3). To increase the statistical power of the power motive measure we pooled the items from the five subscales and used the 20-item index which follows as a measure of explicit power motivation (Cronbach's $\alpha=.68$ ): the difference between the mean score of the four power approach subscales (power dominance: e.g., "Other people often prefer me to be the leader"; integrative power: "During arguments, I can usually think of a way to get the other person to agree with me"; controlled power: "When I want to convince someone of something, I first develop a strategy"; and intuitive power: "I feel comfortable around others when I am in charge") minus the power avoidance subscale score (anxious power: e.g., "When someone behaves very assertively, I hold myself back").

Among the personality scales given to the participants there were four scales measuring mood, each beginning "Right now I feel ..." using a Likert scale ranging from not at all (0) to very much (3). Each subscale has three items. The scales were: Distress (strained, worried, tense; Cronbach's $\alpha=.73$ ); Helplessness (helpless, sad, gloomy; Cronbach's $\alpha=.71$ ); Happiness (happy, pleased, cheerful; Cronbach's $\alpha=.85$ ); Activation (active, alert, energetic;
Cronbach's $\alpha=.72$ ). We calculated the sum scores for each scale (range: $0-9$ ).

\section{Procedure}

The materials were sent via email by IMPART individually to the participants as separate packed files that had to be installed on their personal computers using the installation instructions provided. After the participants had carried out the tasks, the response files, including written feedback and coaching, were sent back via email.

\section{Results}

The descriptive statistics of the results, separated by occupation and sex, are presented in Table 1. We first examined the assumption that persons involved in sales should have high scores in charming personality by comparing their scores with those of the population norms $(M=5.62$, $S D=2.61$; range 0-12). We conducted the comparisons separately for sales representatives $(M=7.95, S D=2.43)$ and for executive managers $(M=7.07, S D=2.59)$. The onesample $t$-test for sales representatives was $t(168)=12.54$, $p<.001, d=1.93, r=.70$. The one-sample $t$-test for executive managers was $t(274)=9.36, p<.001, d=1.13, r=.49$. Note that, although each sample of participants had significantly higher scores in charming personality than the population norms, the mean score was higher and the effect size substantially stronger for sales representatives than for executive managers.

We used a hierarchical regression analysis to evaluate our main hypothesis of a relation between occupation and charming personality scores. Because sex also predicts the charming personality (Kuhl \& Kazén, 2009), it was included in the analyses. In the first step of the analysis we entered occupation (executive manager, sales representative) and sex (female, male), and at the second step the occupation by sex interaction, to predict charming personality. The results are presented in the upper panel of Table 2. Occupation and sex

Table 1

Charming Personality Scores of Participants in Study 1 as a Function of Occupation and Sex

\begin{tabular}{lccc}
\hline & $\begin{array}{c}\text { Sales representatives } \\
(n=169)\end{array}$ & $\begin{array}{c}\text { Executives } \\
(n=275)\end{array}$ & $\begin{array}{c}\text { All managers } \\
(N=444)\end{array}$ \\
\cline { 2 - 4 } & Mean $(S D)$ & Mean $(S D)$ & Mean $(S D)$ \\
\hline Female & $9.02(1.96)$ & $8.02(2.18)$ & $8.42(2.15)$ \\
Male & $7.42(2.47)$ & $6.63(2.65)$ & $6.92(2.61)$ \\
Female and male & $7.95(2.43)$ & $7.07(2.59)$ & $7.40(2.56)$ \\
\hline
\end{tabular}

Note. Range of scores is $0-12$. 
Table 2

Hierarchical Regression Analyses on Charming Personality (Upper Panel) and on Power Motivation (Lower Panel) as a Function of Occupation (Executives, Sales Representatives), Sex (Female, Male), and their Interaction for Study $1(N=444)$

\begin{tabular}{|c|c|c|c|c|c|}
\hline Charming personality & $B$ & $S E B$ & $\beta$ & $R^{2}$ & $\Delta R^{2}$ \\
\hline Step 1 & & & & $.10^{* * *}$ & \\
\hline Constant & 8.70 & 0.55 & & & \\
\hline Occupation & 0.85 & 0.24 & $.16^{* * *}$ & & \\
\hline Gender & -1.47 & 0.25 & $-.27^{* * *}$ & & \\
\hline Step 2 & & & & $.10^{* * *}$ & .001 \\
\hline Constant & 8.21 & 1.31 & & & \\
\hline Occupation X Gender & -0.21 & 0.51 & -.09 & & \\
\hline Power motive & $B$ & $S E B$ & $\beta$ & $R^{2}$ & $\Delta R^{2}$ \\
\hline Step 1 & & & & $.03 * * *$ & \\
\hline Constant & 0.66 & 0.62 & & & \\
\hline Occupation & 0.56 & 0.27 & $.10^{*}$ & & \\
\hline Gender & 0.87 & 0.28 & $.14^{* *}$ & & \\
\hline Step 2 & & & & $.03 * * *$ & .002 \\
\hline Constant & 2.07 & 1.48 & & & \\
\hline Occupation X gender & 0.60 & 0.51 & .23 & & \\
\hline
\end{tabular}

Note. $\beta=$ standardized coefficients; $B=$ the unstandardized coefficients; $R^{2}$ $\left(\Delta R^{2}\right)=$ the cumulative (change in) variance accounted for at each step; $S E B=$ the standard errors of the unstandardized coefficients for the variables in the final regression equation.

${ }^{*} p<.05, * * p<.005, * * * p<.001$.

had significant effects $(p<.001)$, indicating that the charming personality scores were higher for sales representatives than for executive managers and also for women than for men (see also the descriptive statistics in Table 1). The interaction between occupation and sex, evaluated in the second step, was not significant.

In parallel with the above, we carried out another hierarchical regression analysis to predict power motivation, to evaluate our additional hypothesis that sales representatives should have higher scores than executive managers on that variable. The results are shown in the lower panel of Table 2 . As in the previous analysis, the results were significant for occupation $(p<.05)$ and $\operatorname{sex}(p<.005)$, indicating that power motivation scores were stronger for sales representatives than for executive managers and also for men than for women in the first step of the analysis. The interaction of these variables, evaluated in the second step, was not significant.

Notably, the two parallel hierarchical regression analyses, using as the predicted variables assertive and ambitious personality, respectively, did not produce any significant results for the main factors of occupation, sex, or their interaction.

We computed the correlation coefficients for all participants among the variables in the study. The results and descriptive statistics of the variables investigated are presented in Table 3. All correlations were significant
Table 3

Descriptive Statistics and Intercorrelations among the Main Variables of Study $1(N=444)$

\begin{tabular}{lcccccc}
\hline & 1 & 2 & 3 & 4 & $M$ & $S D$ \\
\hline (1) Charming personality & $(.70)$ & $.27^{* *}$ & $.31^{* *}$ & $.46^{* *}$ & 7.40 & 2.56 \\
(2) Assertive personality & & $(.76)$ & $.31^{* *}$ & $.44^{* *}$ & 4.57 & 2.37 \\
(3) Ambitious personality & & & $(.70)$ & $.24^{* *}$ & 4.27 & 2.51 \\
(4) Explicit power motive & & & & $(.68)$ & 2.89 & 2.80 \\
$\quad$ index & & & & & & \\
\hline
\end{tabular}

Note. Cronbach's alphas are listed in parentheses in the diagonal. Possible scores for the variables range from zero to 12 , with the exception of the explicit power motive index.

${ }^{* *} p<.001$ (two-tailed).

$(p<.001)$. That is, the charming personality style correlated with all of the variables. A meaningful result in line with our hypothesis is the correlation between the charming personality and our measure of explicit power motivation (.44), which is the highest in Table 3. The power motive also correlated strongly with the assertive personality (.43), which is not surprising. As expected from the viewpoint of discriminant validity, the correlation between power motivation and ambitious personality was much lower (.24). Moreover, the difference between these two last dependent correlations was significant, $t(441)=3.85, p<.001$.

The correlations between the charming personality style and mood yielded significant relations with positive mood: happiness, $r(442)=.49, p<.001$, and activation, $r(442)=$ $.40, p<.001$. These correlations were substantial and equally significant considering separately the 142 women (.40 and .33, for happiness and activation, respectively) and the 302 men (.49 and .42, for happiness and activation, respectively). In contrast, the charming personality style did not correlate significantly with negative mood: distress ( $r \mathrm{~s}$ ranged between -.01 and -.09 ) or helplessness ( $r$ s ranged between -.01 and -.05 ).

\section{Discussion}

The results showed that the charming personality was systematically related to the main occupation of the participants. Both executive managers and sales representatives had significantly higher scores on charming personality than the population norms. Sales representatives, however, had a higher mean score on this dimension and a stronger effect size $\left(r=.70 ; r^{2}=.49\right)$ than executive managers $(r=.49$; $\left.r^{2}=.24\right)$.

The hierarchical regression analysis showed that occupation and sex significantly predicted charming personality, and in the expected manner: Sales representatives and 
women had high scores on this dimension (see the upper panels of Table 2 and Table 1 for descriptive statistics), without an interaction of both factors. Note that these results are correlational and were obtained using a cross-sectional and not a longitudinal design, which prevents us from making causal statements, but they are consistent with our expectations. One possible explanation of this effect is that it is attributable to sales representatives having more direct contact with customers, with the advantages of the charming personality style emerging particularly in face-to-face interactions. Over time this advantage, with its associated success, should lead individuals with a charming personality style to gravitate towards professions which involve faceto-face commercial activities. The direction of causation, however, could be the opposite. If the main occupation of the person over years involves sales in face-to-face interactions, it could influence his/her personal interaction style and eventually lead to increased scores in charming personality.

In addition, there were differences in the explicit power motivation between sales representatives and executive managers, with the former having higher scores than the latter, as shown in the lower panel of Table 2. This result may not be self-evident, given that the activity of executive managers is also related to the power motivation, but it fits well with our conception that one needs more of this motivational resource to convince other people to buy a product in face-to-face interactions. Sex also predicted the power motivation in this regression analysis, with higher scores for men than for women, which may not be surprising for persons working in managerial occupations.

There were significant correlations among all of the personality variables in the study (see Table 3 ). The correlation between the charming personality style and the explicit power motive was not only significant but also substantial (.46), which supports our assumption that a core characteristic of the charming personality style relates to the exertion of "power," (i.e., influencing or convincing other people), despite the apparently low face validity that the charming personality style may have with power motivation.

An important result is that only the charming personality, but not the assertive or ambitious personality, produced significant results involving the factor of occupation in the analogous hierarchical regression analyses carried out on those variables. This suggests the specificity and meaningfulness of the charming personality style for distinguishing between sales representatives and executive managers.
Women also had significantly higher scores for charming personality than men in both occupational groups (see Table 1), which replicates previous findings (Kuhl \& Kazén, 2009, Table 13). The lack of interaction between occupation and sex evidenced in Table 2 indicates that these two factors make additive and independent contributions to the resultant strength of an individual's charming personality, perhaps involving different mechanisms. Whereas occupation may increase the charming personality scores through learned patterns of behavior in persuading others to buy a product, sex (i.e., in the case of women) may increase the charming personality scores through nonexplicitly learned intuitive patterns of behavior in interacting with others.

Finally, the charming personality style correlated substantially with the positive mood scales of happiness and activation, even after calculating the scores separately for male and female participants. There were, however, no correlations with the negative mood scales of distress and helplessness. These results therefore support our claim that the charming personality style is associated with positive affect, which is useful in establishing friendly interpersonal relationships.

\section{Study 2}

The charming personality style is characterized by friendly and cheerful verbal and nonverbal behavior, which enhances the person's persuasive impact on others. As such, the charming personality style is likely to facilitate sales performance, which critically depends on effective persuasive attempts. We therefore propose that the charming personality style will be positively related to sales performance. As mentioned in the introduction, Moscoso and Salgado (2004) did not find a relation between this style (which they labeled as "cheerful") and job performance. However, their research used criterion variables that were not based on an objective measure, but on the subjective ratings of supervisors. Thus, it remains an open question as to whether the charming personality style is related to objective indicators of sales performance.

In Study 2, we aimed to show that the charming personality does predict sales performance, using an objective indicator. To this end, we analyzed sales performance and personality data from 139 branch office managers of a large German insurance company over a period of 2 years. Based on the results of the first study, we further proposed that increased power motivation among charming individuals is a possible mechanism that underlies this relation. We therefore 
measured the explicit power motivation in this study and tested whether this motivation mediates the possible relation between the charming personality and sales performance.

\section{Method}

\section{Participants}

One hundred and thirty-nine branch office managers of a large German insurance company (132 men and seven women, mean age $=36.8$ years, $S D=8.11$ years; range 28-62 years) participated in the study. None of them had participated in Study 1. Their participation was voluntary (coordinated by the company). All participants were directly involved in insurance policy sales. The main dependent measure was based on each participant's individual sales performance, as reported to us by the insurance company (see below). The participants filled out a series of questionnaires as part of a performance evaluation study aimed at assessing their personality characteristics as well as their psychological and physical wellbeing. The data collected by IMPART were used for individual coaching. As in Study 1, the participants were informed that their data could be used for research purposes in an anonymous form.

\section{Personality scales}

For the analyses we used the charming personality style of the PSDI, as described in the Method section for Study 1. To measure the power motivation, we used the same index as described in the Method section for Study 1. We also included the positive mood scale of happiness in this study (Cronbach's $\alpha=.82$ ).

\section{Sales performance}

The insurance company provided us with sales performance information for each participant. To comply with internal regulations, the company provided this information in a dichotomous form: "reached sales criterion" or "did not reach sales criterion." The participants who reached the criterion had a score of at least $100 \%$ (up to $180 \%$ ) of the goal set by the company for selling insurance policies in two consecutive years, that is, in 2000 and 2001. Not reaching the sales criterion was defined as having sold less than $80 \%$ of the goal set by the company within the 2-year period. Because the objective measure of sales performance was available in a dichotomous form, we analyzed the data using logistic regression analyses.

\section{Procedure}

At the beginning of the study, the materials were sent via email to the participants as separate packed files that had to be installed on their personal computers using the installation instructions provided. The computer program presented the questionnaires, which the participants answered. After the participants had carried out the tasks, the response files were sent back via email. A summary output of the results was sent to the participants and to the coordinator of the study in the company for which the participants worked. Additional information concerning sales performance was provided by the company coordinator to IMPART at the end of the study (approximately 2 years later). The data were organized and given to us for analysis by IMPART.

\section{Results}

To test our main hypothesis, we carried out a logistic regression analysis on sales performance with charming personality as a predictor, yielding the following results. The model chi-square $\left(\chi^{2}\right)$ was 18.5 with $1 d f(p<.001)$. The model $\chi^{2}$ is the difference between the $-2 \log$-likelihood of the null or constant-only model and the $-2 \log$-likelihood of the model with the predictor variable(s), and tests the null hypothesis that all of the regression coefficients in the model are equal to zero (Cizek \& Fitzgerald, 1999). A significant $\chi^{2}$ indicated that the model that included the charming style as a predictor classified participants as good or bad salespersons significantly better than the null model. The Hosmer and Lemeshow Goodness of Fit test was not significant, indicating a good model fit: $\chi^{2}(8)=5.85, p=.66(n s)$. The Cox and Snell $R^{2}$ index was .13 and the Nagelkerke $R^{2}$ was .17 . Using the charming personality as a predictor, the model could classify $68.3 \%$ of the sample as either good or bad salespersons. This model was able to better classify good salespersons $(85.7 \%$ correctly classified) than bad salespersons ( $46.8 \%$ correctly classified). More detailed results of the logistic regression model (coefficient, standard error of the coefficient, odds ratio and Wald statistic) are presented in Table 4. The Wald statistic was significant, corroborating the above results.

To examine the possible role of explicit power as a mediator between charming personality and sales performance, we first checked whether the correlation between each pair of variables (i.e., predictor, mediator, and criterion) was signifi-

\section{Table 4}

Summary of the Logistic Regression Analysis of the Charming Personality Style Predicting Sales Performance for Study 2 ( $N=139)$

\begin{tabular}{ccccc}
\hline & $\beta$ & $S E$ & $O R$ & Wald statistic \\
\hline Charming personality & 0.107 & 0.027 & 1.112 & $15.35^{* *}$ \\
\hline
\end{tabular}

$*^{* *} p<.001$. 


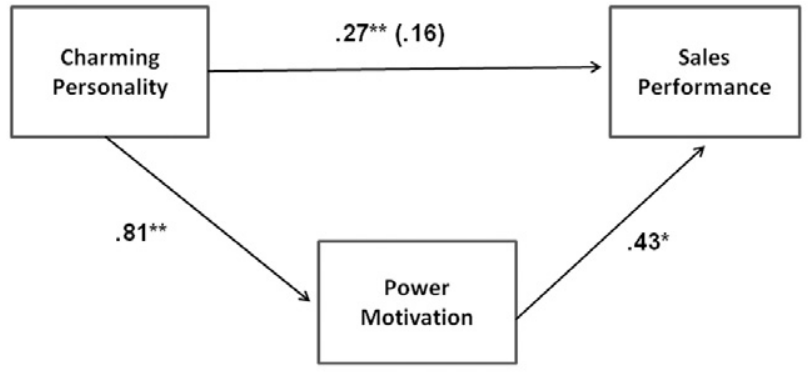

Sobel: $Z=2.63, p<.005$

Figure 1. The mediation model with explicit power motivation as a mediator between charming personality and the dichotomous measure of sales performance in Study $2(N=139)$. The path coefficients are standardized and made comparable across ordinary linear and logistic regression. $Z=$ modified Sobel test of significance of mediation. ${ }^{*} p<.025,{ }^{* *} p<.001$.

cant, which is a precondition to carry out a mediation analysis (Baron \& Kenny, 1986). This was the case. The pointbiserial correlation between the charming personality style and the dichotomous measure of sales performance was positive and significant, $r(137)=.35, p<.001$. The correlation between charming personality and power motivation was significant, $r(137)=.48, p<.001$, and of equivalent magnitude as in Study 1 (see Table 3). Finally, the pointbiserial correlation between power motivation and the dichotomous measure of sales performance was also significant, $r(137)=.32, p<.001$.

We wanted to conduct a mediation analysis using a dichotomous variable as the outcome and continuous variables as the predictor and mediator, which is not standard (see MacKinnon, 2008). To perform this analysis, we used SPSS syntax files and an Excel spreadsheet obtained from a webpage posted by Nathaniel R. Herr (page no longer available). According to Herr, the equations used for the analyses are based on the previous work of MacKinnon and Dwyer (1993). The results of the mediation analysis using Herr's procedure are presented in Figure 1. The path coefficients were standardized to make them comparable across ordinary linear and logistic regressions. The main findings showed that the direct path between the charming personality and sales performance was highly significant (.27), but that this relation was reduced when the power motivation was simultaneously entered in the logistic regression (.16). This drop in prediction was significant, according to the Sobel (1982) test $(p<.005)$, which supports the partial mediating role of the explicit power motivation in the relation between charming personality and actual sales performance.

Although our theory predicts that the influence of the charming personality style on sales performance is mediated by the power motivation, the reverse could also be true. ${ }^{2} \mathrm{We}$ therefore carried out a similar logistic regression analysis using power motivation as the predictor and charming personality as the mediator in order to predict sales performance. The results were significant. The direct path between power motivation and sales performance was significant (.54), but was reduced when charming personality was simultaneously entered in the logistic regression (.24). The drop in prediction was significant, according to the Sobel test $(p<.005)$, suggesting that the charming personality partially mediates the relation between the power motivation and sales performance.

Finally, the correlation between the charming personality style and the positive mood scale of happiness was significant and almost as strong as in the previous study, $r(145)=.45, p<.001$. Because there were only seven women in this sample, it was not possible to calculate reliably this correlation separately by sex.

\section{Discussion}

The results of this study show that the charming personality style significantly predicts the long-term sales performance of branch office managers of an insurance company who are involved in direct contact with potential clients. This main finding contrasts with the negative results reported by Moscoso and Salgado (2004), who did not find a relation between a similar style (which they call "cheerful") and job performance. Their study, however, used supervisors' ratings of employee's performance as a criterion. Supervisors' ratings of job performance may be confounded by subjective factors that are unrelated to actual performance. For instance, the free-spirited character of individuals with a charming personality could have negatively influenced those ratings (Sperry, 1995). The present results show that the charming personality is a long-term predictor of sales performance even when using a stringent objective indicator of performance: reaching or not reaching the criterion of sales success set out by the company over a period of 2 years.

Our second aim was to explore a potential mediator of the relation between charming personality and sales success. The results confirmed our expectations by showing that our measure of explicit power motivation serves as partial mediator for this relation (see Figure 1). When power motivation was added as a predictor in the analysis, there was a significant drop in the relation between charming personality and sales performance, according to the Sobel test. Moreover, the reverse was also true. The power motivation predicted the sales performance and was partially mediated by 
charming personality. This bidirectional finding suggests that power motivation and charming personality are so closely interconnected (or even integrated) that they form a functional network of reciprocal interaction between powermotivated behavior (to have an impact on others) and charming behavior (to be friendly and establish a rapport between salesperson and customer).

That power plays a central role within this reciprocal functional network may appear counterintuitive when talking about employees who are usually characterized as "charming" or "cheerful." However, power motivation takes many forms, some of them subtle, and a core feature involves the motivation to influence other people or to convince them to change their behavior to reach a particular goal (McClelland, 1985). If the goal consists of selling a product or of making people aware of the benefits of changing their behavior in one way or another, then people who score high in charming personality have a better chance of succeeding than people who do not.

In Study 2, we also found a substantial and significant correlation between the charming personality style and the positive mood scale of happiness (.45), replicating the findings of the previous study. This result confirms that the charming style is associated with positive affect, which is a useful resource in face-to-face interactions.

\section{Study 3}

Our theoretical model holds that the charming personality style facilitates direct but subtle efforts aimed at influencing others, something that should prove beneficial in a sales context. In this study we sought to provide a first test of this notion under the relatively controlled conditions of a laboratory setting. The participants were videotaped while performing a simulated sales task. The videotapes were rated afterwards by independent judges for persuasiveness and for the nonverbal and paralinguistic behaviors related to persuasiveness (Schultheiss \& Brunstein, 2002). We hypothesized that the charming personality style not only would predict greater verbal persuasiveness but also more persuasive nonverbal/ paralinguistic behavior.

\section{Method}

\section{Participants and design}

Thirty-nine paid volunteers at the VU University Amsterdam ( 23 women, 16 men, average age 22 years) participated in the experiment.

\section{Materials}

\section{Personality}

The participants rated their personality styles using the short version of the PSDI (Kuhl \& Kazén, 2009; Cronbach's $\alpha=.63$ ). The relevant scales of this test are described in the Method section for Study 1.

\section{Global impressions}

The independent observers rated their global impressions of the participants' persuasiveness and personality, based on Schultheiss and Brunstein (2002). Judgments of the participants' competence, differentiation, impact, and intelligence were combined into a score for persuasiveness (Cronbach's $\alpha=.89$ ). Likewise, the raters' judgments of the participants' extraversion, activity, impulsiveness, and dominance were combined into an assertiveness score (Cronbach's $\alpha=.84$ ). Finally, the raters judged the participants' friendliness.

\section{Verbal fluency}

Following Schultheiss and Brunstein (2002), two raters independently assessed speech and behavioral characteristics on five items using a seven-point bipolar scale. Because the interrater agreement was high ( $>.70$ for all ratings), we averaged the judgments of both raters. The participants' speech characteristics were assessed in terms of speed (slow vs. fast), volume (quiet vs. loud), smoothness (halting vs. smooth), melody (monotonous vs. melodic) and pitch (high vs. low). These ratings were combined into a verbal persuasiveness index (Cronbach's $\alpha=.72$ ).

\section{Nonverbal behavior}

Also following Schultheiss and Brunstein (2002), the two raters coded the participants' behavior on more objective behavioral aspects. This coding included eye contact (i.e., whether or not participants made eye contact with the camera), eyebrow lifts (i.e., the number of observable lifts), frowns (i.e., the number of observable frowns), gestures (i.e., whether or not the participants made six or more gestures during the film), movements (i.e., whether or not the participants moved before the camera). These nonverbal behaviors did not form a coherent underlying dimension (Cronbach's $\alpha<.60$ ), so we analyzed them separately.

\section{Procedure}

The experiment took place in an observation room. This room consisted of two adjacent rooms that were separated by a one-way mirror screen. This enabled the experimenter to 
observe the participants without being noticed by them. A camera was placed in front of the screen and a computer was placed against a wall. The participants were tested in individual sessions that lasted approximately $75 \mathrm{~min}$.

On arrival, the participants were led to a computer. The experimenter explained that the information regarding the study and the instructions were administered using the computer. The experimenter also pointed out that the room was connected with the adjacent room so that questions could be asked by means of an intercom. This ensured that the participants were aware they could be observed. Then the experimenter left the room. The participants were informed that they would participate in several unrelated studies that were allegedly administered together for efficiency reasons. Next, the participants moved on to the first study on "personality."

On completion of the questionnaires, the participants moved on to the next study regarding "persuasiveness." The participants were informed about a new mobile phone provider. To this end the provider offered three different types of subscriptions with a special discount for students. The participants were asked to make a 5-min film advertising one of the phone subscriptions. The participants were informed that the films would be judged on their persuasiveness by a panel of psychologists and marketing experts. The participants were led to believe that these judges were present in the adjacent observation room (there were no judges in the adjacent room). The most persuasive film would win an iPod or its monetary equivalent. In the following 10 -min preparation time the participants were asked to think of and write down persuasive arguments for one of the subscriptions. When the time was up, the participants were asked to take a seat before the camera. After the experimenter started the recorder the participant was told to start her/his 5-min presentation. Finally, the participants were fully debriefed, paid, and thanked for their efforts.

\section{Results}

The data from one participant ( $2.6 \%$ of the entire sample) could not be analyzed due to a failure of the video equipment. Thus, the analyses were performed on 38 participants. The descriptive statistics and correlations for the main variables are shown in Table 5 .

\section{Charming personality style and persuasiveness}

As can be seen in Table 5, the charming personality style was a significant predictor of persuasiveness. The relevant correlation was moderately strong, $r(38)=.36, p=.029$. Thus, the higher the participants scored on the charming personality style, the more persuasive they were perceived to be during their sales presentation by the independent raters.

\section{Potential mediating role of verbal fluency}

Table 5 also shows that verbal fluency was significantly correlated with the charming personality style, $r(38)=.36$, $p=.027$, and with persuasiveness, $r(38)=.55, p=.0001$. Thus, verbal fluency qualifies as a potential mediator of the effect of the charming personality style on persuasiveness. To test the possible mediating role of verbal fluency, we simultaneously regressed the charming personality style and verbal fluency on persuasiveness. This analysis revealed that the effect of verbal fluency remained highly significant, $\beta=.62, t(1,35)=3.96, p=.0004$, while the effect of the charming personality style dropped to nonsignificance, $\beta=.02, t(1,35)=.12, p=.752$. According to the Sobel test, this mediation effect was significant. Thus, the greater

Table 5

Zero-order Correlations between Observer Judgments of Participants' Persuasiveness, Personality Impressions, and Non-verbal Behavior, and the Charming Personality Style for Study 3

\begin{tabular}{|c|c|c|c|c|c|c|c|c|c|c|c|c|}
\hline Variables & $M$ & $S D$ & 1 & 2 & 3 & 4 & 5 & 6 & 7 & 8 & 9 & 10 \\
\hline 1. Persuasiveness & -0.07 & 1.76 & 1 & & & & & & & & & \\
\hline 2. Assertiveness & 0.28 & 1.34 & $.69 * * *$ & 1 & & & & & & & & \\
\hline 3. Friendliness & 1.04 & 1.65 & $.45^{* * *}$ & $.48^{* * *}$ & 1 & & & & & & & \\
\hline 5. Eye contact & 1.92 & 0.88 & $-.41 * * *$ & $-.50 * * *$ & $-.33^{*}$ & $-.50 * * *$ & 1 & & & & & \\
\hline 6. Eyebrow lifts & 7.50 & 10.64 & $.57 * * *$ & $.48^{* * *}$ & $.40^{* *}$ & $.37 * *$ & -.23 & 1 & & & & \\
\hline 7. Frowns & 0.43 & 0.94 & .09 & -.07 & -.13 & -.05 & .04 & -.16 & 1 & & & \\
\hline 10. Charming style & 6.37 & 1.26 & $.36^{* *}$ & $.65^{* * *}$ & $.27 *$ & $.55 * * *$ & $-.5 l^{* * *}$ & .22 & -.10 & $-.47 * * *$ & $-.30 *$ & 1 \\
\hline
\end{tabular}

$* p \leq .10, * * p \leq .05, * * * x \leq .01$ (two-tailed). 
persuasiveness of highly (relative to lower) charming participants was statistically explained by the greater verbal fluency of highly charming individuals.

To further decompose the effect of verbal fluency, we repeated the mediation analysis while substituting verbal fluency with its five component measures of talking speed, volume, smoothness, melody, and pitch. This analysis yielded significant effects of smoothness, $\beta=.39, t(1$, $35)=3.45, p=.0016$, and melody, $\beta=.74, t(1,35)=4.28$, $p=.0002$. Thus, the greater persuasiveness of highly (relative to lower) charming participants was statistically explained by the greater smoothness and melody in the speeches of highly charming individuals.

\section{Potential mediating role of nonverbal behavior}

Table 5 shows that several nonverbal behaviors were significantly correlated with the charming personality style. To test the possible mediating role of nonverbal behaviors, we simultaneously regressed the five measures of nonverbal behaviors (eye contact, eyebrow lifts, frowns, gestures, and movements) on the participants' rated persuasiveness. This analysis revealed a positive effect of eyebrow lifts, $\beta=.29$, $t(1,32)=2.10, p=.043$, which indicated that the participants were rated as more persuasive when they lifted their eyebrows more often. In addition, there was a negative effect of gesturing, $\beta=-.49, t(1,32)=-3.38, p=.0002$, which indicated that the participants were rated as less persuasive when they gestured more often.

To test if eyebrow lifts and gesturing mediated the effect of the charming personality style, we simultaneously entered all three variables as predictors of persuasiveness. This analysis yielded significant effects of eyebrow lifts, $\beta=.30$, $t(1,34)=2.17, p=.038$, and gesturing, $\beta=-.50, t(1$, $34)=3.22, p=.0028$, while the effect of the charming personality style was no longer significant, $\beta=.06, t(1$, $34)=.44, p=.666$. According to the Sobel test, this mediation effect was significant. Thus, the number of eyebrow lifts and gesturing mediated the effect of the charming personality style on persuasiveness.

\section{Additional analyses}

The charming personality style was further strongly and significantly related to perceived assertiveness, $r(38)=.65$, $p=.001$. The latter relation is nontrivial, because whereas the charming personality style was rated by the participants themselves, their assertiveness was rated by the independent observers from the videotaped sales presentation. Finally, the charming style was marginally related to friendliness, $r(38)=.27, p=.097$. This pattern of correlations is consistent with the idea that the charming style is primarily related to socially dominant interactions with a positive affective tone. In addition, it is compatible with the findings of the previous two studies concerning substantial correlations between the charming personality and the positive mood scales of happiness and activation (Study 1).

\section{Discussion}

Using a controlled laboratory setting, Study 3 provides further evidence that the charming personality style predicts greater persuasiveness in a sales task, as rated by independent observers. Moreover, these results showed that charming individuals displayed more verbal fluency, particularly smoother and more melodic speech, and more frequent eyebrow lifts and less frequent gesturing during the sales task. These verbal and nonverbal behaviors statistically mediated the effect of the charming personality style on persuasiveness As such, the results of Study 3 help us to understand what makes charming individuals persuasive. In particular, it appears that the charming personality style is associated with verbal and nonverbal behaviors that increase the individual's persuasive powers.

\section{General discussion}

The present research shows the relevance of the charming personality style to occupational activities and sales performance. In Study 1 we found that the charming personality style predicted more involvement in occupational activities that involve face-to-face contact with customers. In Study 2 we found that the charming personality style predicted actual sales performance among the branch office managers of a large German insurance company over a period of 2 years, and that this relation was partially mediated by the explicit power motive. Finally, in Study 3 we showed that the charming personality style predicted greater persuasiveness, verbal fluency, and gesturing in a simulated sales task. These results are therefore consistent with our main hypotheses, as presented in the introductory section. In addition, our claim that the charming personality style is related to a positive and cheerful mood and that it is closely associated with the power motivation was supported by these studies.

The positive link between the charming personality style and job fitting and sales performance in this research suggests that at least some personality styles may have a positive 
influence on job performance. What are the possible mechanisms by which the charming personality style facilitates sales performance? We propose: (a) an increased level of positive affect, with its "emotional contagion" effect (Barsade, 2002); and (b) the intuitive implementation of the power motive, which should promote goal attainment in face-to-face interactions.

As we found in each study, the charming personality style is characterized by increased positive affect. Positive affect has been related to a series of useful resources that promote interpersonal interactions, within and outside organizational settings (Lyubomirsky, King, \& Diener, 2005). Among others are creativity (Isen, Daubman, \& Nowicki, 1987), receptivity to new information (Estrada, Isen, \& Young, 1997), helping behavior (George, 1991, 1998), and positive emotional contagion at the individual and group levels (Barsade, 2002). Because the charming personality is characterized by positive affect we suggest that it does relate positively to the above traits or behaviors, and future studies should investigate this proposal.

Because the charming personality style is characterized by an increased power motive (influencing other persons), as we consistently found in the studies in which the power motive was assessed (i.e., Studies 1 and 2), it should be a useful resource for persons in management positions. Some results of Study 1 are consistent with this proposal: All participants, not only sales representatives but also executive managers, had significantly higher scores on the charming personality than the population norms. Moreover, we found that a heightened power motivation served as a partial mediator to predict higher sales performance among charming individuals (Study 2), as indicated by the mediation analysis presented in Figure 1.

At a more general level, the present research calls into question whether personality styles necessarily reflect the "dark side" of human personality (Moscoso \& Salgado, 2004). The results showed that the charming personality style can have an adaptive value in organizations, particularly in regard to sales success. It thus seems important to distinguish between personality styles and personality disorders. We conceptualize personality styles as enduring traits with unique patterns of thoughts, feelings, and behavior (see also Winter, 2011). In our view, any given personality style is likely to be adaptive in some contexts and maladaptive in other contexts. For instance, the conscientious style (related to the obsessive-compulsive personality), if not extreme, may be positively valued in bureaucratic organizations, because of the orderliness and attention to detail that characterize this style. At the same time, the conscientious style may be negatively valued in work teams, because individuals with this style are often condescending to peers.

It should be mentioned that even the negative effects of personality styles (e.g., self-conscious or avoidant styles) can turn into positive effects when such "negative" styles are associated with efficient emotion regulation (Baumann, Kaschel, \& Kuhl, 2007). By contrast, personality disorders by definition refer to significant functional impairments in the individual's functioning. Personality disorders may thus indeed reflect the "dark side" of personality, whereas personality styles can be more or less adaptive, depending on the match between situational demands and the particular style. A classification system proposed by Millon (1994; see also Strack, 1999) is consistent with our position concerning the positive aspects of personality styles (Kuhl \& Kazén, 2009), in contrast to personality disorders, on a series of occupations and real-world settings. Nonetheless, there is a need for more systematic research to examine whether personality styles other than the charming style may have advantages in specific work environments (cf. Sperry, 1995).

\section{Practical implications}

The present findings may have substantial practical significance. A direct implication of this research is that employees with high scores in charming personality are expected to be more successful in jobs in which eye-to-eye contact with clients is needed than in jobs which do not require face-to-face interaction. This conclusion is suggested by the results of Study 1 .

The company with which the research for Study 2 was conducted hires approximately 2,000 new salespersons per year and loses approximately $75 \%$ of them within a 2-year period, for a variety of reasons. Among the obvious reasons are poor sales performance and poor personal adjustment to stressful conditions, for instance, due to changes within the company or within the general economy. Thus, there seems to be ample room for improvement in the process of selecting and training salespeople, at least within this particular company. Employers may use the charming personality style as a criterion in selecting more effective salespeople and in designing job characteristics that optimally fit the profile of charming employees (Kuhl, Scheffer, Mikoleit, \& Strehlau, 2010). Additionally, training interventions may be adapted to the differential needs of individuals who score high versus low on the charming personality style (Kuhl et al., 2006; 
Leach, Liu, \& Johnston, 2005). We emphasize that the charming personality style is likely to be particularly relevant for occupations that depend on interpersonal influence. In other kinds of occupations, the charming personality style may barely contribute to job performance (Moscoso \& Salgado, 2004), or could even lower job performance (e.g., in bureaucratic organizations, cf. Sperry, 1995).

\section{Notes}

1. The Charming Personality Scale and other scales of the PSDI can be requested from the authors to be used for research purposes.

2. We thank an anonymous reviewer for this suggestion.

\section{References}

American Psychiatric Association. (2000). Diagnostic and statistical manual of mental disorders (4th ed., text rev.). Washington, DC: American Psychiatric Association.

Baron, R. M., \& Kenny, D. A. (1986). The moderator-mediator variable distinction in social psychological research: Conceptual, strategic, and statistical considerations. Journal of Personality and Social Psychology, 51, 1173-1182. doi:10.1037| 0022-3514.51.6.1173

Barsade, S. G. (2002). The ripple effect: Emotional contagion and its influence on group behavior. Administrative Science Quarterly, 47(4), 644-675. doi:10.2307/3094912

Baumann, N., Kaschel, R., \& Kuhl, J. (2007). Affect sensitivity and affect regulation in dealing with positive and negative affect Journal of Research in Personality, 41, 239-248. doi:10.1016/ j.jrp.2006.05.002

Berridge, K. C. (2003). Pleasures of the brain. Brain and Cognition, 52, 106-128. doi:10.1016/S0278-2626(03)00014-9

Cizek, G. J., \& Fitzgerald, S. M. (1999). An introduction to logistic regression. Measurement and Evaluation in Counseling and Development, 31, 223-245.

DeShon, R. P., \& Gillespie, J. Z. (2005). A motivated action theory account of goal orientation. Journal of Applied Psychology, 90, 1096-1127. doi:10.1037/0021-9010.90.6.1096

Elliot, A. J., \& Thrash, T. M. (2002). Approach-avoidance motivation in personality: Approach and avoidance temperaments and goals. Journal of Personality and Social Psychology, 82, 804818. doi:10.1037/0022-3514.82.5.804

Estrada, C. A., Isen, A. M., \& Young, M. J. (1997). Positive affect facilitates integration of information and decreases anchoring in reasoning among physicians. Organizational Behavior and Human Decision Processes, 72, 117-135. doi:10.1006/obhd. 1997.2734

Fiedler, P. (1998). Persönlichkeitsstörungen [Personality disorders] (4th ed.). Weinheim, Germany: Psychologie Verlags Union.

Friedman, H. S., Riggio, R. E., \& Casella, D. F. (1988). Nonverbal skill, personal charisma, and initial attraction. Personality and Social Psychology Bulletin, 14, 203-211. doi:10.1177/ 0146167288141020

George, J. M. (1991). State or trait: Effects of positive mood on prosocial behaviors at work. Journal of Applied Psychology, 76, 299-307. doi:10.1037/0021-9010.76.2.299

George, J. M. (1998). Salesperson mood at work: Implications for helping customers. Journal of Personal Selling and Sales Management, 18(3), 23-30.

Gray, J. A. (1987). The psychology of fear and stress (2nd ed.). Cambridge, UK: Cambridge University Press.

Hogan, R. (2005). In defense of personality measurement: New wine for old whiners. Human Performance, 18, 331-341. doi:10.1207/s15327043hup1804_1

Isen, A. M., Daubman, K. A., \& Nowicki, G. P. (1987). Positive affect facilitates creative problem solving. Journal of Personality and Social Psychology, 52(6), 1122-1131. doi:10.1037/00223514.52.6.1122

Isen, A. M., Shalker, T. E., Clark, M., \& Karp, L. (1978). Affect, accessibility of material in memory, and behavior: A cognitive loop? Journal of Personality and Social Psychology, 36, 1-12. doi:10.1037/0022-3514.36.1.1

Kanfer, R., \& Hulin, C. L. (1985). Individual differences in successful job searches following lay-off. Personnel Psychology, 38, 835-847. doi:10.1111/j.1744-6570.1985. tb00569.x

Kazén, M., \& Kuhl, J. (2011). Directional discrepancy between implicit and explicit power motives is related to well-being among managers. Motivation and Emotion, 35(3 [Special issue on implicit motives]), 317-327. doi:10.1007/s11031-0119219-8

Kozhevnikov, M. (2007). Cognitive styles in the context of modern psychology: Toward an integrated framework of cognitive style. Psychological Bulletin, 133, 464-481. doi:10.1037/0033-2909. 133.3.464

Kuhl, J. (2000). The volitional basis of personality systems interaction theory: Applications in learning and treatment contexts. International Journal of Educational Research, 33, 665-703. doi:10.1016/S0883-0355(00)00045-8

Kuhl, J. (2001). Motivation und Persönlichkeit: Interaktionen Psychischer Systeme [Motivation and personality: Interactions of mental systems]. Göttingen, Germany: Hogrefe.

Kuhl, J., \& Henseler, W. (2004). Entwicklungsorientiertes Scanning (EOS) [Development-oriented scanning (EOS)]. In L. von Rosenstiel \& J. Erpenbeck (Eds.), Handbuch der Kompetenzmessung (pp. S428-S453). Heidelberg, Germany: Spektrum Akademischer Verlag.

Kuhl, J., \& Kazén, M. (2009). Persönlichkeits-Stil-und-StörungsInventar (PSSI): Handanweisung 2. Auflage [Personality Styles and Disorders Inventory (PSDI): Manual] (2nd ed.). Göttingen, Germany: Hogrefe.

Kuhl, J., Kazén, M., \& Koole, S. L. (2006). Putting self-regulation theory into practice: A user's manual. Applied Psychology: An International Review, 55, 408-418. doi:10.1111/j.1464-0597. 2006.00260.x

Kuhl, J., Scheffer, D., Mikoleit, B., \& Strehlau, A. (2010). Persönlichkeitsdiagnostik und Motivationsförderung: Anwendung der PSI-Theorie in der Personalentwicklung [Job motivation and assessment: Applying PSI theory to personnel development]. Stuttgart, Germany: Kohlhammer. 
Leach, M. P., Liu, A. H., \& Johnston, W. J. (2005). The role of self-regulation training in developing the motivation management capabilities of salespeople. Journal of Personal Selling and Sales Management, 25, 269-281.

Lynch, T. R., \& Horton, L. E. (2004). Personality disorders. In J. C. Thomas \& M. Hersen (Eds.), Psychopathology in the workplace: Recognition and adaptation (pp. 147-160). New York: Brunner-Routledge.

Lyubomirsky, S., King, L., \& Diener, E. (2005). The benefits of frequent positive affect: Does happiness lead to success? Psychological Bulletin, 131(6), 803-855. doi:10.1037/0033-2909. 131.6.803

MacKinnon, D. P. (2008). Introduction to statistical mediation analysis. New York, NY: Lawrence Erlbaum Associates.

MacKinnon, D. P., \& Dwyer, J. H. (1993). Estimating mediated effects in prevention studies. Evaluation Review, 17, 144-158. doi:10.1177/0193841X9301700202

McClelland, D. C. (1985). Human motivation. Glenview, IL: Scott, Foresman \& Co.

Miao, C. F., \& Evans, K. R. (2007). The impact of salespersons' motivation on role perceptions and job performance: A cognitive and affective perspective. Journal of Personal Selling and Sales Management, 27, 89-101. doi:10.2753/PSS0885-3134270106

Millon, T. (1994). Millon index of personality styles. San Antonio, TX: The Psychological Corporation.

Millon, T., \& Davis, R. (2000). Personality disorders in modern life. New York, NY: John Wiley \& Sons.

Moscoso, S., \& Salgado, J. F. (2004). "Dark side" personality styles as predictors of task, contextual, and job performance. International Journal of Selection and Assessment, 12, 356-362. doi:10.1111/j.0965-075X.2004.00290.x

Mount, M. K., Barrick, M. R., \& Stewart, G. L. (1998). Five-factor model of personality and performance in jobs involving interpersonal interactions. Human Performance, 11, 145-165. doi:10.1080/08959285.1998.9668029
Ones, D. S., Viswesvaran, C., \& Dilchert, S. (2005). Personality at work: Raising awareness and correcting misconceptions. Human Performance, 18, 389-404. doi:10.1207/s15327043hup1804_5

Schultheiss, O. C., \& Brunstein, J. C. (2002). Inhibited power motivation and persuasive communication: A lens model analysis. Journal of Personality, 70, 553-582. doi:10.1111/14676494.05014

Sobel, M. E. (1982). Asymptotic confidence intervals for indirect effects in structural equation models. In S. Leinhardt (Ed.), Sociological methodology (pp. 290-312). Washington DC: American Sociological Association.

Sperry, L. (1995). Personality styles in the workplace. Individual Psychology, 51, 422-439.

Strack, S. (1999). Millon's normal personality styles and dimensions. Journal of Personality Assessment, 72, 426-436. doi: 10.1207/S15327752JP720307

Vinchur, A. J., Schippmann, J. S., Switzer, F. S., III, \& Roth, P. L. (1998). A meta-analytic review of predictors of job performance for sales people. Journal of Applied Psychology, 83, 586-597. doi:10.1037/0021-9010.83.4.586

Warr, P., Bartram, D., \& Martin, A. (2005). Personality and sales performance: Situational variation and interactions between traits. International Journal of Selection and Assessment, 13, 87-91. doi:10.1111/j.0965-075X.2005.00302.x

Winter, D. G. (2011). Philosopher-king or polarizing politician? A personality profile of Barack Obama. Political Psychology, 32, 1059-1081. doi:10.1111/j.1467-9221.2011.00852.x

Wise, R. A., \& Rompre, P. P. (1989). Brain dopamine and reward. Annual Review of Psychology, 40, 191-225. doi:10.1146/ annurev.ps.40.020189.001203

World Health Organization. (2008). ICD-10: International statistical classification of diseases and related health problems (10th revision, 2008 ed.). New York, NY: Author. 